\title{
RESEARCH
}

Open Access

\section{ECMO-treatment in patients with acute lung failure, cardiogenic, and septic shock: mortality and ECMO-learning curve over a 6-year period}

Norbert Banjas ${ }^{1}$, Hans-Bernd Hopf ${ }^{2}$, Ernst Hanisch', Benjamin Friedrichson², Julia Fichte ${ }^{2}$ and Alexander Buia ${ }^{1 *}$ (I)

\begin{abstract}
Background: Based on promising results over the past 10 years, the method of extracorporeal membrane oxygenation (ECMO) has developed from being used as a 'rescue therapy' to become an accepted treatment option for patients with acute lung failure (ARDS). Subsequently, the indication was extended also to patients suffering from cardiogenic and septic shock. Our aim was to evaluate hospital mortality and associated prognostic variables in patients with lung failure, cardiogenic, and septic shock undergoing ECMO. Furthermore, a cumulative sum (CUSUM) analysis was used to assess the learning curve of ECMO-treatment in our department.

Methods: We retrospectively analysed the data of 131 patients undergoing ECMO treatment in the intensive care unit of the Asklepios Hospital of Langen over the time period from April 2011 to July 2016. We categorised the patients into three groups: lung failure $(n=54)$; cardiogenic shock $(n=58)$; and septic shock $(n=19)$. The primary outcome variable was hospital mortality along with identification of prognostic variables on mortality before initiating ECMO using logistic regression. Second outcome variable was the learning curve of our department in patients with ECMO.

Results: 6-year hospital mortality was $54 \%$ in patients with lung failure, $59 \%$ in patients with cardiogenic shock, and $58 \%$ in patients with septic shock.

The CUSUM analysis revealed a typical learning curve with a point of inflection in the year 2014. Patients treated before 2014 had a worse outcome ( $p=0.04$ whole cohort; $p=0.03$ for lung failure). Furthermore, less than 20 treatments per year respectively treatment before 2014 were associated negatively with hospital mortality of lung failure patients showing an odds ratio of 4.04, as well as in the entire cohort with an odds ratio of 3.19.

Conclusion: For the first time, a steep ECMO-learning curve using the CUSUM tool has been described. Obviously, the experience with ECMO has to be taken into account when defining the role of ECMO in ARDS, cardiogenic, and septic shock.
\end{abstract}

Keywords: Extracorporeal membrane oxygenation, CUSUM-learning curve, Mortality, Predictors, ARDS, Cardiogenic shock, Septic shock

\footnotetext{
* Correspondence: a.buia@t-online.de

${ }^{1}$ Department of Visceral and Thoracic Surgery, Asklepios Klinik Langen,

Röntgenstr 20, 63220 Langen, Germany

Full list of author information is available at the end of the article
}

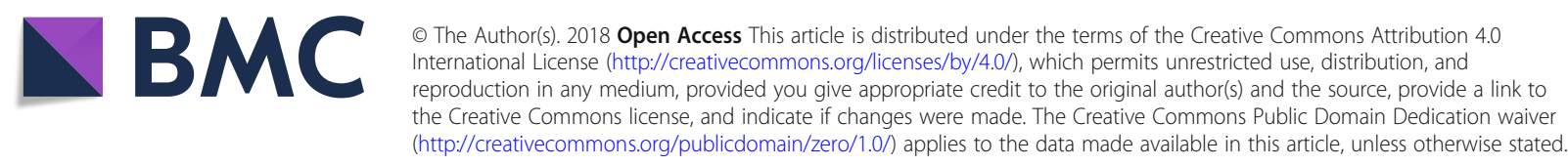




\section{Background}

In addition to its application as veno-venous (vv-) ECMO in cases of severe lung failure, ECMO is now accepted as a treatment option in the form of veno-arterial (va) or venovenous-arterial (vva) ECMO for patients with cardiogenic shock [1]. Current guidelines on respiratory failure and cardiogenic shock in the context of myocardial infarction now recommend ECMO treatment as a 'rescue therapy' for severe cases [2, 3], even if, as in the case of patients with cardiogenic shock, there is still only limited evidence for its effectiveness $[2,4]$. In fact, the number of veno-arterial and veno-venous ECMO treatments over the last few years has risen substantially both in Germany and around the world $[5,6]$. Whilst the use of ECMO in patients with ARDS or cardiogenic shock at least as rescue therapy is an accepted approach, little data are available regarding its use in adult patients suffering from septic shock, with survival rates varying between $15 \%$ and $71 \%$ [7-10].

Accordingly, our first objective was to assess hospital mortality in our patients with acute lung failure, cardiogenic, and septic shock treated by ECMO and to identify pre-ECMO variables associated with good or poor outcome respectively, i.e. which patients probably might benefit from ECMO and which not. Second objective was to evaluate whether in a complex medical procedure like ECMO a 'learning curve' can be observed with increasing routine and patients per year.

\section{Methods}

\section{Study design}

We analysed the data of 131 patients in a retrospective cohort study from April 2011 to July 2016, treated with a veno-venous ECMO (vv-ECMO), veno-arterial ECMO (va-ECMO) or veno-venous-arterial ECMO (vva-ECMO) in the Asklepios Hospital Langen. We divided our patients in three indication groups: acute lung failure, cardiogenic, and septic shock. The presentation of the study has been carried out following STROBE guidelines (Strengthening the Reporting of Observational Studies in Epidemiology) [11]. The study was approved by the Ethics Commission of the State Medical Council of Hessen (file reference no. $88 / 2017)$.

\section{Setting}

The Asklepios Hospital in Langen is a teaching hospital of the Goethe University in Frankfurt am Main with 10 departments, 401 beds, and > 16,000 in-patients per year. ECMO treatment is carried out on the interdisciplinary intensive care unit, led by anesthesiology, with 14 artificialrespiration beds, equipped with haemodiafiltration and dialysis treatment options. Data collection was carried out between November 2017 and January 2018.

The ECMO treatment team made all decisions regarding treatment with ECMO. Where respiratory insufficiency was the sole indication, the treatment was carried out as vv-ECMO. In patients with septic or cardiogenic shock, the treatment was carried out as va-ECMO or vva-ECMO. Cannulations were guided by ultrasound imaging. In the vv-ECMO variant, cannulation was carried out in the right internal jugular vein (15 or 19F) and the femoral vein (23 or $25 \mathrm{~F}$ ), or in cases of AVALON double-lumen cannulas (31F) via the right internal jugular vein alone. In the va-ECMO mode, cannulation was carried out in the femoral artery (15 or $17 \mathrm{~F})$ and vein (23 or $25 \mathrm{~F})$. When applying the vva-ECMO mode, an additional venous cannula was placed in the right internal jugular vein in addition to the cannulas in the femoral artery and vein (15 or $19 \mathrm{~F})$.

\section{Study participants and study size}

We identified 132 patients being treated with ECMO (vv-ECMO, va-ECMO, vva-ECMO) on the intensive care unit of the Asklepios Hospital in Langen. These patients were treated consecutively over the aforementioned time period. Of these, 131 were included in the study: one patient was excluded from the study due to lacking data. We divided patients into three groups:

Group 1 (lung failure) included all patients that received veno-venous ECMO for hypoxic and/or hypercapnic respiratory failure, regardless of the underlying disease. The indication for use of ECMO was based on the Berlin definition of acute lung failure [12] and was determined after having exhausted all conventional treatment options. Patients simultaneously suffering from treatmentrefractory septic shock and treated with vva-ECMO were not included in this group but included in group 3 considering the septic shock to be the primary disease.

Group 2 (cardiogenic shock) included all patients that received va-ECMO treatment for cardiogenic shock. Post-cardiotomy patients were excluded. Cardiogenic shock was defined as persistent hypotension despite adequate volume replacement (ultrasound of inferior vena cava) and the need for noradrenaline infusion at a dose $>0.5 \mu \mathrm{g} / \mathrm{kg} / \mathrm{min}$ in order to maintain a mean arterial blood pressure $\geq 65 \mathrm{mmHg}$.

Group 3 (septic shock) included all patients treated with vva-EMCO to provide both circulatory and respiratory support due to suffering from treatment-refractory septic shock. The definition of septic shock corresponds with the third international consensus definitions for sepsis and septic shock [13]. Criteria for application of vva-ECMO were mean arterial pressure $<65 \mathrm{mmHg}$ and/ or progressive lactic acidosis and end-organ dysfunction despite adequate administration of fluids and increasing noradrenaline infusion $(>0.5 \mu \mathrm{g} / \mathrm{kg} / \mathrm{min})$.

\section{Data sources and variables}

After identification of patients, the following variables were recorded: age, gender, weight, diagnosis and pre-existing 
conditions, blood gas analyses $(\mathrm{pH}, \mathrm{pO} 2$, and $\mathrm{pCO} 2$, base deficit, lactate), need for resuscitation, Simplified Acute Physiology Score (SAPS) II score, Sequential Organ Failure Assessment (SOFA) score, length of hospital and ICU stay, duration of artificial ventilation, need for and number of patients treated with dialysis, and necessity of tracheostomy. Scores and laboratory variables were recorded at comparable times. All the data collected were recorded in a Microsoft Excel database. The primary outcome variable was the hospital mortality in the individual groups along with the identification of prognostic pre-ECMO variables on mortality. Second outcome variable was to assess whether there was a learning curve of the procedure with increasing routine and patient numbers over time.

\section{Statistics}

A cumulative sum chart (CUSUM chart) was used to investigate a possible learning curve. We used the nonrisk-adjusted cumulative observed minus expected failure graph procedure, such as that described by Rogers et al. [14]. The CUSUM curve is calculated on the basis of the following considerations: where the ECMO treatment is successful, $X_{i}=0$; and where the treatment is not successful, and the patient dies over the period of the hospital stay, $X_{i}=1$. On the basis of epidemiological data from Karagiannidis et al. [5], we selected an acceptable error rate for ECMO treatment in Germany, which corresponds to the expected mortality of $p_{0}=0.6$ for a mixed vv and va-ECMO population. The formula for calculation of the CUSUM curve was calculated as follows: $C_{i}=C_{(i-1)}+\left(X_{i}-\right.$ $p_{0}$ ) with $C_{0}=0$. The interpretation of the curve characteristics is carried out as follows: each successful treatment lowers the CUSUM value by $p_{0}$, and the curve drops. Each failed treatment results in an increase of $1-p_{0}$, and the curve rises. Where the actual error rate corresponds to the rate expected, the curve will oscillate along a horizontal axis. Logistic regression was used for identification of variables influencing mortality, specifying the odds ratio (OR) and the confidence interval (CI). Logistic regression was first performed as a univariate analysis. Variables with a significant $p$ value in the univariant analysis were furthermore used for multivariate logistic regression as an additional sensitivity analysis. Due to the small sample size, multivariate analysis was performed in the entire patients and stepwise backwards elimination process was used with $p<0.05$.

The statistical analysis was performed with BiAS (version 11.08, Epsilon-Verlag). The null hypothesis was that there were no differences between the three groups in the recorded variables. The normal distribution verification was carried out using the Kolmogorov-Smirnov-Liliefors test. Quantitative data were specified as median values with interquartile range; nominal data were specified as a frequency $n$ (\%). Differences in medians of quantitative data were analysed with the Kruskal-Wallis test. Differences in categorical variables were tested using the MantelHaenszel test or the $\chi^{2}$ test. The null hypothesis was rejected with a two-tailed $p$ value $<0.05$.

\section{Results}

\section{Demographic data of the patients}

We investigated 131 patients who received ECMO treatment from April 2011 to July 2016. Patients were categorised as follows: group 1 (lung failure) contained 54 patients; group 2 (cardiogenic shock) contained 58 patients; and group 3 (septic shock) contained 19 patients.

Table 1 gives an overview of the demographic and clinical data of the three groups, as well as the distribution of cases before 2014. Table 2 shows the underlying diseases for patients in groups $1-3$.

In group 1, the most common cause of lung failure was an infection of the lungs $(n=31,57 \%)$. The median SOFA score before starting ECMO was 6; the median SAPS II score 40.

In group 2, the most common cause for cardiogenic shock was myocardial infarction $(n=40,69 \%)$. The median SOFA score before starting ECMO was 10; the median SAPS II score 67. The patients in group 2 had the highest SAPS II score when compared with patients from group 1 and group 3 ( $p<0.01$ vs. group 1 ; and $p=0.03$ vs. group 3$)$ and the highest SOFA score when compared with patient from group $1(p<0.01)$.

In group 3, the most common cause of septic shock was infection of the lungs $(n=10,53 \%)$. The second common cause was an abdominal infection $(n=8)$. The causes of abdominal septic shock were anastomotic insufficiency $(n=3)$, pancreatitis $(n=2)$, gastric perforation $(n=1)$, mesenteric vein thrombosis $(n=1)$, and cholangitis $(n=1)$. The median SOFA score was 8 ; the median SAPS II score 42.

\section{Clinical outcomes}

Clinical outcomes are also shown in Table 1. The hospital stays for group 1 (27 days) and group 3 (26 days) were significantly longer than that of group 2 (10 days) (group 1 vs group 2: $p=0.01$; and group 2 vs group 3: $p=0.02$ ) (Table 1). The median duration of ECMO treatment was 11 days for group 1,5 days for group 2, and 14 days for group 3 (group 2 vs groups 1 and $3 p<0.01$ ). Cardiopulmonary resuscitation (CPR) was carried out previously to the ECMO implantation (within a 24-h time frame) in 3 patients in group 1, 38 patients in group 2, and 3 patients in group 3. A bypass operation was carried out in five patients with cardiogenic shock (group 2). In six out of eight patients with septic shock due to abdominal cause abdominal surgery was performed.

Table 3 shows the blood gas analyses both before and 1 day after implantation of the extracorporeal circulation. 
Table 1 Patients and treatment characteristics

\begin{tabular}{|c|c|c|c|c|}
\hline & $\mathrm{RF}, n=54$ & $\mathrm{CS}, n=58$ & $S S, n=19$ & $p$ value \\
\hline Age, years & $62(53-70)$ & $67(55-73)$ & $62(55-73)$ & 0.28 \\
\hline Weigh, $\mathrm{kg}^{\mathrm{a}}$ & 76.5 (64-102) & 88 (70-99) & $89.5(77-102)$ & 0.33 \\
\hline Male & $29(54)$ & $37(64)$ & $14(74)$ & 0.26 \\
\hline SOFA ${ }^{\mathrm{b}}$ & $6(3-9)$ & $10(8-11)$ & $8(6-12)$ & $<0.01$ \\
\hline SAPS $\|^{c}$ & $40(31-60)$ & $67(48-78)$ & $42(32-61)$ & $<0.01$ \\
\hline \multicolumn{5}{|l|}{ Comorbidities } \\
\hline -Art. hypertension & $33(61)$ & $34(60)$ & $8(42)$ & 0.33 \\
\hline -Coronary disease & $7(13)$ & $40(70)$ & $4(21)$ & $<0.01$ \\
\hline -Diabetes mellitus & $11(20)$ & $16(28)$ & $2(11)$ & 0.26 \\
\hline -Hyperlipidaemia & $4(7)$ & $8(14)$ & $5(26)$ & 0.11 \\
\hline -Kidney injury & $7(13)$ & $2(4)$ & $1(5)$ & 0.16 \\
\hline$-\mathrm{COPD}$ & $26(48)$ & $3(5)$ & $4(21)$ & $<0.01$ \\
\hline Duration of hospitalisation, days & $27(15-40)$ & $10(4-36)$ & $26(18-67)$ & $<0.01$ \\
\hline Duration of ICU stay, days & $20(8-31)$ & $7(3-25)$ & $20(17-65)$ & $<0.01$ \\
\hline Time on ECMO support, days & $12(5-19)$ & $5(3-8)$ & $14(9-25)$ & $<0.01$ \\
\hline CPR pre-ECMO & $3(6)$ & $38(66)$ & $3(16)$ & $<0.01$ \\
\hline Mechanical ventilation time, $\mathrm{h}$ & $391(122-687)$ & $129(42-413)$ & $423(304-772)$ & $<0.01$ \\
\hline Renal replacement therapy & $36(67)$ & $45(78)$ & $18(95)$ & $<0.05$ \\
\hline Tracheotomy & $33(61)$ & $20(34)$ & $17(89)$ & $<0.01$ \\
\hline Weaning from ECMO & $35(65)$ & $30(52)$ & $10(53)$ & 0.34 \\
\hline Death & $29(54)$ & $34(59)$ & $11(58)$ & 0.86 \\
\hline ECMO-treatment before 2014 & $27(50)$ & $17(29)$ & $1(5)$ & $<0.01$ \\
\hline
\end{tabular}

Data is given as median (interquartile range) and $n(\%)$

$R F$, respiratory failure; CS, cardiogenic shock; SS, septic shock; SOFA, Sequential Organ Failure Assessment; SAPS II, Simplified Acute Physiology Score; COPD, chronic obstructive lung disease; $C P R$, cardiopulmonary resuscitation

${ }^{\mathrm{a}}(n=48$ in $\mathrm{RF}, n=46$ in $\mathrm{CS})$

$\mathrm{b}(n=50$ in RF, $n=56$ in CS)

${ }^{\mathrm{c}}(n=51$ in RF, $n=56$ in CS)

The $\mathrm{pH}$ value significantly improved and showed standard values after 1 day of ECMO treatment. Also, all other values improved within the first $24 \mathrm{~h}$.

\section{Mortality}

The 6-year hospital mortality for the entire study population was 56\%. In group 1, 29 of 54 patients died (54\%), in group 2, 34 of 58 (59\%), in group 3, 11 of 19 (58\%) (Table 1). Patients with septic shock due to abdominal infection compared with lung infection had the worst prognosis: six out of eight patients died. Patients with septic shock due to lung infection survived in 5 of 10 cases. The patient with the soft tissue infection survived. Withdrawal of ECMO was successful in 35 of 54 cases in group 1, in 30 of 58 cases in group 2, and 10 of 19 cases in group 3.

Since national guidelines for the treatment of respiratory insufficiency recommended at least 20 ECMO treatments per year [2], we investigated how many patients have been treated by us each year: in the years from 2011 to 2016, we treated $10,16,19,27,32$, and 27 patients respectively.
We subsequently examined how many patients had died in the 3 -year period with $<20$ patients per year. In fact, in the period 2011-2013, 31 of the 45 patients treated died (69\%), whereas in the period 2014 to 2016, only 43 of 86 patients treated died (50\%) ( $p=0.04)$. With respect to the groups $1-3$, this effect was also apparent in groups 1 and 2, although not significant in group 2 . In the period 2011-2013, 19 of 27 patients from group 1 died (70\%), whereas in the period 2014-2016, only 10 of 27 patients died $(37 \%)(p=0.03)$.

In group 2, 12 of 17 patients (71\%) died in the time period from 2011 to 2013, whereas in the 2014-2016 time period, 22 of 41 patients died (54\%) ( $p=0.37)$.

For the septic shock group, no comparison could be made since most of the patients with septic shock were treated in the period 2014-2016.

Figure 1 shows our CUSUM learning curve. Mortality rate initially increased followed by a horizontal progression, relating to a mortality rate which corresponds with the expected mortality rate $p_{0}=0.6$, in addition to a final section, with a falling curve indicating the learning effect 
Table 2 Aetiology of respiratory failure, cardiogenic shock and septic shock

\begin{tabular}{|c|c|c|c|c|}
\hline & $\mathrm{RF}, n=54$ & $C S, n=57$ & SS, $n=19$ & $p$ value \\
\hline Pneumonia & $31(57.41)$ & - & $10(52.63)$ & 0.41 \\
\hline Intra-abdominal infection & $4(7.41)$ & - & $8(42.11)$ & $<0.01$ \\
\hline Soft tissue infection & $1(1.85)$ & - & $1(5.26)$ & 0.49 \\
\hline Trauma & $1(1.85)$ & - & - & - \\
\hline Cardiac decompensation & $6(11.11)$ & - & - & - \\
\hline Shock & $3(5.56)$ & - & - & - \\
\hline Decompensated chronic lung disease & $3(5.56)$ & - & - & - \\
\hline Other & $5(9.25)$ & - & - & - \\
\hline Acute myocardial infarction & - & $41(70.69)$ & - & - \\
\hline Cardiomyopathy & - & $4(6.9)$ & - & - \\
\hline Pulseless electrical activity & - & $4(6.9)$ & - & - \\
\hline Pulmonary emboli & - & $3(5.17)$ & - & - \\
\hline Ventricular fibrillation & - & $2(3.45)$ & - & - \\
\hline Myocarditis & - & $1(1.72)$ & - & - \\
\hline Other & - & $3(5.17)$ & - & - \\
\hline
\end{tabular}

Data is given as $n(\%)$

$R F$, respiratory failure; $C S$, cardiogenic shock; SS, septic shock

with a reduced mortality rate. This downward trend of the curve begins in the year 2014.

Table 4 shows the results from the univariate logistic regression analysis of the variables recorded before application of ECMO with respect to hospital mortality.

In patients with lung failure, age (OR 1.07, CI 1.01-1.12; $p=0.01)$, number of patients treated per year $(<20 / \mathrm{a})(\mathrm{OR}$ 4.04; CI 1.27-12.86; $p=0.02$ ), and the year of performing ECMO (OR 0.65; CI $0.45-0.93 ; p=0.02)$ were significantly associated with hospital mortality. In patients with cardiogenic shock, age (OR 1.08; CI 1.02-1.13; $p=<0.01$ ), SAPS II score (OR 1.03; CI 1-1.06; $p=0.03$ ), $\mathrm{pH}$ value (OR 0.22; CI $0-0.66 ; p=0.03$ ), serum lactate value (OR 1.03; CI
$1.01-1.05 ; p=<0.01$ ), base excess (OR 0.89; CI 0.82$0.97 ; p=0.01$ ), and hyperlipidaemia (OR 0.07; CI $0.01-$ $0.64 ; p=0.02$ ) were associated with hospital mortality.

In patients with septic shock, no variables could be identified that were associated with an increased hospital mortality.

Table 5 shows the multivariate logistic regression analysis results of pre-ECMO variables associated with hospital mortality. In the multivariate logistic regression after backward elimination with $p<0.05$, three variables remained statistically significant on hospital mortality in the whole patients' population; age (OR 1.08; CI 1.04-1.12; $p<0.01$ ), less than 20 patients per year (OR 3.19; CI 1.19-8.51; $p=$

Table 3 Blood gas analysis pre ECMO and 1 day after ECMO initiation

\begin{tabular}{|c|c|c|c|c|}
\hline Pre-ECMO & $\mathrm{RF}, n=46$ & $\mathrm{CS}, n=49$ & SS, $n=17$ & $p$ value \\
\hline $\mathrm{pH}^{\mathrm{a}}$ & $7.25(7.18-7.35)$ & $7.11(6.95-7.25)$ & $7.21(7.11-7.3)$ & $<0.01$ \\
\hline $\mathrm{pCO} 2, \mathrm{mmHG}$ & $67(54-83)$ & $52(42-68)$ & $64(53-84)$ & $<0.01$ \\
\hline $\mathrm{BE}, \mathrm{mmol} / \mathrm{l}$ & $2(-5$ to 8$)$ & $-14(-21$ to -5$)$ & $-4(-8$ to -1$)$ & $<0.01$ \\
\hline Lactate, mg/dl & $13(8-26)$ & $73(34-114)$ & $29(13-62)$ & $<0.01$ \\
\hline $\mathrm{pO} 2 / \mathrm{FiO}^{\mathrm{b}}$ & $145(99-233)$ & $158(83-254)$ & $111(77-147)$ & 0.23 \\
\hline 1 day after ECMO initiation & RF $n=48$ & $\operatorname{CS} n=44$ & SS, $n=19$ & $p$ value \\
\hline $\mathrm{pH}, \mathrm{mmHg}$ & $7.40(7.35-7.46)$ & $7.39(7.34-7.44)$ & $7.42(7.38-7.49)$ & 0.43 \\
\hline $\mathrm{pCO} 2, \mathrm{mmHg}$ & $48(43-52)$ & $42(40-45)$ & $47(44-49)$ & $<0.01$ \\
\hline $\mathrm{BE}, \mathrm{mmol} / \mathrm{l}$ & 6 (2 to 9$)$ & $1(-1$ to 3$)$ & $4(2$ to 10$)$ & $<0.01$ \\
\hline Lactate, mg/dl & $13(9-21)$ & $22(16-34)$ & $17(14-35)$ & $<0.01$ \\
\hline $\mathrm{pO} 2 / \mathrm{FiO} 2$ & 199 (163-262) & $278(180-472)$ & $168(117-260)$ & $<0.01$ \\
\hline
\end{tabular}

Data is given as median (interquartile range)

$R F$, respiratory failure; $C S$, cardiogenic shock; $S S$, septic shock; $B E$, base excess a $(n=47$ in RF)

${ }^{\mathrm{b}}(n=47$ in RF, $n=43$ in CS, $n=16$ in SS) 


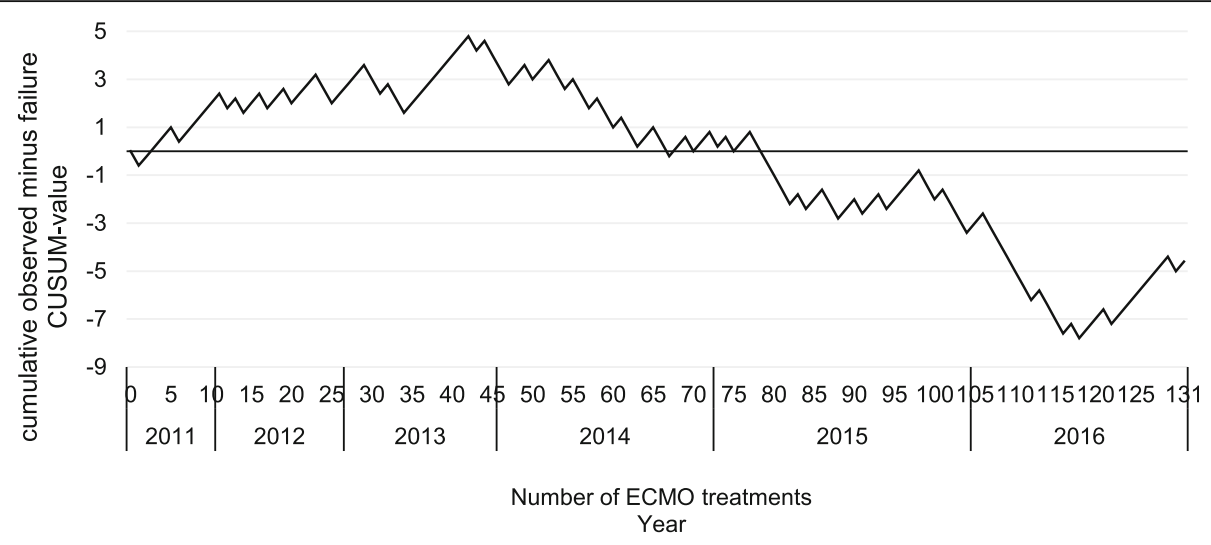

Fig. 1 Cumulative observed minus failure (CUSUM) chart for in-hospital mortality after ECMO treatment. Legend: the vertical axis shows the CUSUM value, which increases for each failure or decreases on each success. The horizontal axis shows the number of ECMO treatments and the corresponding year. Expected failure rate was set at the expected mortality rate of $60 \%$ based on the data of the epidemiologic study of Karagiannidis et al. for a mixed vv- and va-ECMO population in Germany [5]. An upward slope represents a failure rate higher than expected and a downward slope represents a failure rate fewer than expected. With a failure rate equal the expected failure rate, the CUSUM curve should oscillate around a horizontal axis

0.02 ) and pre-ECMO lactate (OR 1.01; CI 1-1.02; $p=0.03$ ) were negatively associated with hospital mortality.

\section{Discussion}

Our data in patients treated with ECMO showed an overall 6-year hospital mortality of $54 \%$ for patients with lung failure, $59 \%$ in patients with cardiogenic shock and $58 \%$ for patients in septic shock. We were able to show that there is a typical learning curve for the use of the ECMO in our department (Fig. 1). The CUSUM analysis furthermore supports the assumption of a case numberdependent survival rate.

The hospital mortality of patients with lung failure ranges from 39 to $70 \%$ [5, 15-19]. Of note, the median average age in 4 of the 6 studies was 44 years, and as such was almost 18 years less than in our study. Thus, the patient's age seems to be a significant negative prognostic variable on hospital mortality and may explain the mortality differences between these studies and our data. In fact, both the 2013 and 2017 ELSO guidelines specified an increased age as a relative contraindication for both vv-ECMO as well as va-ECMO, even though no specific cut-off age has been stated [1, 20]. A major difference to other studies seems to be the condition of the patients prior to the ECMO treatment. The median SOFA score of patients published previously was 12 [16-18], whereas this score was 6 points for the patients investigated in the present study. One reason for this could be that the decision for treatment was carried out at an early stage in our study. The comparatively high

Table 4 Univariate logistic regression of predictors for in-hospital mortality

\begin{tabular}{|c|c|c|c|c|c|c|}
\hline & \multicolumn{2}{|l|}{ RF } & \multicolumn{2}{|l|}{ CS } & \multicolumn{2}{|l|}{ SS } \\
\hline & Odds ratio $(\mathrm{Cl})$ & $p$ & Odds ratio $(\mathrm{Cl})$ & $p$ & Odds ratio $(\mathrm{Cl})$ & $p$ \\
\hline$\overline{\mathrm{Age}^{a}}$ & $1.07(1.01-1.12)$ & 0.01 & $1.08(1.02-1.13)$ & 0.01 & $1.04(0.96-1.13)$ & 0.30 \\
\hline Year $^{\mathrm{a}}$ & $0.65(0.45-0.93)$ & 0.02 & $0.88(0.59-1.31)$ & 0.51 & $2.28(0.62-8.42)$ & 0.22 \\
\hline$<20$ patients/years ${ }^{\mathrm{a}}$ & $4.04(1.27-12.86)$ & 0.02 & $2.07(0.61-7.1)$ & 0.25 & NA & NA \\
\hline SAPS $\|^{\mathrm{b}}$ & $1(0.97-1.03)$ & 0.93 & $1.03(1-1.06)$ & 0.03 & $0.99(0.94-1.04)$ & 0.71 \\
\hline $\mathrm{pH}$ pre-ECMO ${ }^{c}$ & $0.55(0.01-50.19)$ & 0.79 & $0.22(0-0.66)$ & 0.03 & $0.21(0-1118)$ & 0.72 \\
\hline Base excess pre-ECMO ${ }^{d}$ & $0.94(0,86-1.03)$ & 0.17 & $0.89(0.82-0.97)$ & 0.01 & $1.04(0.88-1.22)$ & 0.69 \\
\hline Lactate pre-ECMO & $1.02(0.99-1.05)$ & 0.27 & $1.03(1.01-1.05)$ & $<0.01$ & $0.99(0.95-1.02)$ & 0.34 \\
\hline Hyperlipidaemia $^{f}$ & $2.77(0.26-29.72)$ & 0.40 & $0.07(0.01-0.64)$ & 0.02 & $0.37(0.04-3.4)$ & 0.38 \\
\hline
\end{tabular}

$R F$, respiratory failure; CS, cardiogenic shock; SS, septic shock; SAPS II, Simplified Acute Physiology Score; Cl, confidence interval

${ }^{\mathrm{a}}(n=54$ in RF, $n=58$ in CS, $n=19$ in SS)

$\mathrm{b}_{(n=51}$ in RF, $n=56$ in CS, $n=19$ in SS)

${ }^{\mathrm{C}}(n=47$ in RF, $n=49$ in CS, $n=17$ in SS)

${ }^{\mathrm{d}}(n=46$ in RF, $n=49$ in CS, $n=17$ in SS)

e $(n=46$ in RF, $n=49$ in CS, $n=17$ in SS)

f $(n=54$ in RF, $n=57$ in CS, $n=19$ in SS) 
Table 5 Multivariate logistic regression of predictors for in-hospital mortality in entire patients

\begin{tabular}{|c|c|c|c|c|}
\hline & \multicolumn{2}{|c|}{ Univariate logistic regression } & \multicolumn{2}{|c|}{ Multivariate logistic regression } \\
\hline & Odds ratio $(\mathrm{Cl})$ & $p$ & Odds ratio $(\mathrm{Cl})$ & $p$ \\
\hline Age & $1.07(1.03-1.1)$ & $<0.01$ & $1.08(1.04-1.12)$ & $<0.01$ \\
\hline$<20$ patients/years & $2.21(1.03-4.76)$ & 0.04 & $3.19(1.19-8.51)$ & 0.02 \\
\hline Base excess pre-ECMO & $0.96(0.92-1)$ & 0.03 & & \\
\hline Lactate pre-ECMO & $1.01(1-1.02)$ & 0.01 & $1.01(1-1.02)$ & 0.03 \\
\hline
\end{tabular}

Univariate logistic regression was performed in entire patients $(n=131)$ except for base excess pre-ECMO and lactate pre-ECMO $(n=112)$

median $\mathrm{PaO} 2 / \mathrm{FiO} 2$ ratio before ECMO treatment in our patients, compared with a $\mathrm{PaO} 2 / \mathrm{FiO} 2$ ratio $<100 \mathrm{mmHg}$ in the case of the aforementioned studies, can be explained by the fact that in our patients with lung failure, 26 patients exhibited hypercapnic lung failure but only a moderate oxygenation impairment (Horowitz quotient $>150 \mathrm{mmHg}$ ).

In our patients with cardiogenic shock, the actual hospital mortality (59\%) was considerably lower than the predicted mortality (75\%) [21], suggesting a substantial survival benefit of va-ECMO as has been shown in comparable studies [22-26]. The duration of ECMO administration in patients with cardiogenic shock was significantly shorter than in patients with lung failure or patients with septic shock, which might be explained by a rapid stabilisation of the patient by ECMO-treatment. In fact, within the first $24 \mathrm{~h}$, the serum lactate levels (as a marker of tissue perfusion) decreased significantly [27]. Additionally, in comparable studies of patients with cardiogenic shock, the duration of treatment also was only a few days [22, 24], which can in all likelihood be explained by a rapid recovery of the pumping function of the heart, accompanied by an improvement in end-organ perfusion. Consistent with these findings, serum lactate and $\mathrm{pH}$ values in our study were variables associated with hospital mortality. This correlation has also been established in other studies [23, 26, 28].

Hospital mortality in septic shock patients treated with va-ECMO is heterogeneous. Published data show in-hospital mortality rates of $78-85 \%$ [7, 9], which is higher compared to the hospital mortality of $58 \%$ in the present study. There are exceptions: Bréchot et al. performed av-ECMO in patients with septic shock resulting in a hospital mortality rate of only $29 \%$ [10]. Since increasing age is negatively associated with survival, the result of Brechot et al. might be explained by the median age of 45 years, significantly lower than the age of patients from other studies, including our study. The extension to vva-ECMO mode was administered in cases of patients with septic shock and ARDS to achieve both efficient oxygenation as well as sufficient haemodynamic support. For example, Yeo et al. performed vva-ECMO in eight patients with ARDS and septic shock (mean age 51 years) of whom four survived, i. e., a mortality rate similar to our results [8]. Since severe sepsis/septic shock are often associated with acute lung failure [29], vva-ECMO might have an advantage over va-ECMO. However, this concept has to be proven yet.

We found a clear relationship between the number of treated patients and the survival rate. However, we cannot distinguish some clear-cut reasons for this finding. National guidelines for the treatment of respiratory insufficiency published in 2016 recommend that centres providing ECMO therapy should treat at least 20 patients per year [2]. In our patients, hospital mortality in the period 2014-2016 fell with > 20 ECMO treatments per year from $69 \%$ to $50 \%$; in patients with lung failure, this fall was even more pronounced: $70 \%$ to $37 \%$. Consistent with this, the CUSUM curve shows a downward trend (after an initial rise and short horizontal phase), starting in 2014. This downward trend reflects a lower mortality rate than expected, suggesting that a minimum number of ECMO treatments per year is a prerequisite for successful ECMO treatment. Furthermore, less than 20 treatments per year respectively the treatment before 2014 were associated negatively with hospital mortality of lung failure patients showing an odds ratio of 4.04 (Table 4) and in the entire cohort with an odds ratio of 3.19 (Table 5). This case number-dependent probability of survival in patients treated with ECMO can also be found in the ELSO registry. Centres with more than 30 patients per year exhibit significantly lower death rates than centres with a number of cases per year of 5 or less [30]. Finally, in the CESAR study, all ARDS patients were transferred to a specialised centre with greater experience in the ECMO treatment [19], and as such, the high number of cases performed by this hospital may have contributed to the better survival rate.

Our investigation has limitations. First, it is a singlecentre study with a relatively small number of cases and a retrospective study design. Second, the decision to apply an ECMO therapy is made on a case-by-case basis by the treating doctor. Third, a standardised protocol defining when an ECMO therapy indication applies does not exist, which may lead to selection bias. This also applies for the time of implantation, which is decided solely on the basis of the treating physician's best judgement. Fourth, our inhomogeneous cohort due to a wide range of underlying diseases may limit the significance of our findings. Finally, it should be noted that in $29 \%$ of 
patients, there are some missing data, mostly blood gas analysis results, which also limit the conclusiveness of the study.

\section{Conclusion}

Our study has shown that in patients with acute lung failure, cardiogenic, and septic shock undergoing ECMO treatment, there are three major variables associated with hospital mortality: age, pre-ECMO lactate, and experience with the procedure. The CUSUM analysis shows that there is a case- and time-dependent learning curve for the usage of ECMO therapy. In our hospital, it took about 3 years and about 50 treatments to get a change in the gradient of the learning curve. Accordingly, one factor determining outcome in patients with ECMO is obviously the experience of the ECMO centre.

\section{Abbreviations}

ARDS: Adult respiratory distress syndrome; Cl: Confidence interval; CUSUM: Cumulative Sum; ECMO: Extracorporeal membrane oxygenation; OR: Odds ratio; SAPS: Simplified Acute Physiology Score; SOFA: Sequential Organ Failure Assessment

\section{Acknowledgements}

Not applicable

\section{Funding}

None.

\section{Availability of data and materials}

The datasets supporting the conclusions of this article are available in the Mendeley Data repository, https://doi.org/10.17632/3f8dj24hwy.1

\begin{abstract}
Authors' contributions
NB provided the acquisition of data, did the analysis and interpretation of the data, and drafted the manuscript. $A B$ and $E H$ contributed to the data interpretation, and drafted and revised the manuscript. BF and JF contributed to the study conception and design and in the acquisition of data. $\mathrm{HBH}$ drafted and revised the manuscript. All authors read and approved the final manuscript.
\end{abstract}

\section{Ethics approval and consent to participate}

The study was approved by the Ethics Commission of the State Medical Council of Hesse [Ethikkommission der Landesärztekammer Hessen] (file reference no. 88/2017).

\section{Consent for publication}

Not applicable.

\section{Competing interests}

The authors declare that they have no competing interests.

\section{Publisher's Note}

Springer Nature remains neutral with regard to jurisdictional claims in published maps and institutional affiliations.

\section{Author details}

'Department of Visceral and Thoracic Surgery, Asklepios Klinik Langen, Röntgenstr 20, 63220 Langen, Germany. '2Department of Anaesthesia and Peri-operative Medicine, Asklepios Klinik Langen, Röntgenstr 20, 63220 Langen, Germany.
Received: 27 July 2018 Accepted: 3 December 2018

Published online: 18 December 2018

\section{References}

1. ELSO Adult Cardiac Failure Supplement to the ELSO General Guidelines Extracorporeal Life Support Organization (ELSO) Guidelines for Adult Cardiac Failure. 2013. https://www.elso.org/Portals/0/IGD/Archive/FileManager/ e76ef78eabcusersshyerdocumentselsoguidelinesforadultcardiacfailure1.3.pdf. Accessed 03 Dec 2017.

2. Bauer M, Bein A, Benk T, Bock C, Boeken E, Brückner U, et al. S3-Leitlinie Invasive Beatmung und Einsatz extrakorporaler Verfahren bei akuter respiratorischer Insuffizienz. 2017. http://www.awmf.org/uploads/tx_szleitlinien/ 001-021I_S3_Invasive_Beatmung_2017-12.pdf. Accessed 07 Dec 2017.

3. Ibanez B, James S, Agewall S, Antunes MJ, Bucciarelli-Ducci C, Bueno H, et al. ESC Guidelines for the management of acute myocardial infarction in patients presenting with ST-segment elevation. Eur Heart J. 2017; http:// academic.oup.com/eurheartj/article/doi/10.1093/eurheartj/eh×393/4095042/ 2017-ESC-Guidelines-for-the-management-of-acute Accessed 30 Dec 2017.

4. Vincent J-L, Brochard LJ. Do we need randomized clinical trials in extracorporeal respiratory support? We are not sure. Intensive Care Med. 2017:43(12):1869-71

5. Karagiannidis C, Brodie D, Strassmann S, Stoelben E, Philipp A, Bein T, et al. Extracorporeal membrane oxygenation: evolving epidemiology and mortality. Intensive Care Med. 2016;42(5):889-96.

6. Organization ELS. International summary July 2017. World Magazine. p. 8-8. https://www.elso.org/Registry/Statistics/InternationalSummary.aspx. Accessed 27 Nov 2017.

7. Park TK, Yang JH, Jeon K, Choi S-H, Choi J-H, Gwon H-C, et al. Extracorporeal membrane oxygenation for refractory septic shock in adults. Eur J CardioThoracic Surg. 2015:47(2):e68-74.

8. Yeo HJ, Jeon D, Kim YS, Cho WH, Kim D. Veno-veno-arterial extracorporeal membrane oxygenation treatment in patients with severe acute respiratory distress syndrome and septic shock. Crit Care. 2016;20:28.

9. Huang C-T, Tsai Y-J, Tsai P-R, Ko W-J. Extracorporeal membrane oxygenation resuscitation in adult patients with refractory septic shock. J Thorac Cardiovasc Surg. 2012;146(4):1041-6.

10. Bréchot $N$, Luyt C-E, Schmidt M, Leprince $P$, Trouillet J-L, Léger $P$, et al, Venoarterial extracorporeal membrane oxygenation support for refractory cardiovascular dysfunction during severe bacterial septic shock. Crit Care Med. 2013;41(7):1616-26.

11. Strobe E, Vandenbroucke JP, Von Elm E, Altman DG, Gøtzsche PC, Mulrow $C D$, et al. Strengthening the Reporting of Observational Studies in Explanation and Elaboration. Epidemiology. 2007;18(6):805-35.

12. Ranieri VM, Rubenfeld GD, Thompson BT, et al. Acute respiratory distress syndrome: The berlin definition. JAMA. 2012:307(23):2526-33.

13. Singer M, Deutschman CS, Seymour CW, Shankar-Hari M, Annane D, Bauer $M$, et al. The Third International Consensus Definitions for Sepsis and Septic Shock (Sepsis-3). JAMA. 2016;315(8):801.

14. Rogers CA, Reeves BC, Caputo M, Saravana Ganesh J, Robert Bonser FS, Gianni Angelini FD. Control chart methods for monitoring cardiac surgical performance and their interpretation. J Thorac Cardiovasc Surg Mosby. 2004;128:811-9.

15. Brogan TV, Thiagarajan RR, Rycus PT, Bartlett RH, Bratton SL. Extracorporeal membrane oxygenation in adults with severe respiratory failure: a multicenter database. Intensive Care Med. 2009;35(12):2105-14.

16. Schmid C, Philipp A, Hilker M, Rupprecht L, Arlt M, Keyser A, et al. Venovenous extracorporeal membrane oxygenation for acute lung failure in adults. HEALUN. 2012;31:9-15.

17. Panholzer B, Meckelburg K, Huenges K, Hoffmann G, von der Brelie M, Haake N, Pilarczyk K, Cremer J, Haneya A. Extracorporeal membrane oxygenation for acute respiratory distress syndrome in adults: an analysis of differences between survivors and non-survivors. Perfusion. 2017;32(6):495-500.

18. Enger TB, Philipp A, Lubnow M, Fischer M, Camboni D, Lunz D, et al. Longterm survival in adult patients with severe acute lung failure receiving venovenous extracorporeal membrane oxygenation. Crit Care Med. 2017;45(10): $1718-25$.

19. Peek GJ, Mugford M, Tiruvoipati R, Wilson A, Allen E, Thalanany MM, et al. Efficacy and economic assessment of conventional ventilatory support versus extracorporeal membrane oxygenation for severe adult respiratory failure (CESAR): a multicentre randomised controlled trial. Lancet. 2009;374:1351-63. 
20. Extracorporeal Life Support Organization (ELSO) Guidelines for Adult Respiratory Failure. 2017. https://www.elso.org/Portals/0/

ELSO\%20Guidelines\%20For\%20Adult\%20Respiratory\%20Failure\%201_4.pdf Accessed 03 Dec 2017.

21. Le Gall J-R, Lemeshow S, Saulnier FA. New Simplified Acute Physiology Score (SAPS II) Based on a European/North American Multicenter Study. JAMA. 1993;270(24):2957.

22. Schmidt M, Burrell A, Roberts L, Bailey M, Sheldrake J, Rycus PT, et al. Predicting survival after ECMO for refractory cardiogenic shock: the survival after veno-arterial-ECMO (SAVE)-score. Eur Heart J. 2015;36(33):2246-56.

23. Kim H, Lim S-H, Hong J, Hong Y-S, Lee CJ, Jung J-H, et al. Efficacy of veno-arterial extracorporeal membrane oxygenation in acute myocardial infarction with cardiogenic shock. Resuscitation. 2012;83:971-5.

24. Combes A, Leprince P, Luyt C-E, Bonnet N, Trouillet J-L, Léger P, et al. Outcomes and long-term quality-of-life of patients supported by extracorporeal membrane oxygenation for refractory cardiogenic shock. Crit Care Med. 2008;36(5):1404-11.

25. Aso S, Matsui H, Fushimi K, Yasunaga H. In-hospital mortality and successful weaning from venoarterial extracorporeal membrane oxygenation: analysis of 5263 patients using a national inpatient database in Japan. Crit Care. 2016;20(1):80

26. Silva $P$, Caeiro D, Fernandes $P$, Guerreiro $C$, et al. Extracorporeal membrane oxygenation in circulatory and respiratory failure-a single-center experience PALAVRAS-CHAVE. Rev Port Cardiol. 2017;36(11):833-42.

27. Weil MH, Tang W, Rackow EC, Halfman CJ, Bruno SJ. Forty-five-year evolution of stat blood and plasma lactate measurement to guide critical care. Clin Chem. 2009;55(11):2053-4.

28. Enger TB, Philipp A, Videm V, Lubnow M, Wahba A, Fischer M, et al. Prediction of mortality in adult patients with severe acute lung failure receiving veno-venous extracorporeal membrane oxygenation: a prospective observational study. Crit Care. 2014;18(2):R67.

29. Rubenfeld GD, Caldwell E, Peabody E, Weaver J, Martin DP, Neff M, et al. Incidence and Outcomes of Acute Lung Injury. N Engl J Med. 2005;353(16): 1685-93.

30. Barbaro RP, Odetola FO, Kidwell KM, Paden ML, Bartlett RH, Davis MM, et al. Association of hospital-level volume of extracorporeal membrane oxygenation cases and mortality. Analysis of the extracorporeal life support organization registry. Am J Respir Crit Care Med. 2015;191(8):894-901.

Ready to submit your research? Choose BMC and benefit from:

- fast, convenient online submission

- thorough peer review by experienced researchers in your field

- rapid publication on acceptance

- support for research data, including large and complex data types

- gold Open Access which fosters wider collaboration and increased citations

- maximum visibility for your research: over $100 \mathrm{M}$ website views per year

At $\mathrm{BMC}$, research is always in progress.

Learn more biomedcentral.com/submissions 